\section{Nociones del espacio interior entre las Lógicas de Coherencia Espacial y La Percepción Visual. El interiorismo de Zaha Hadid}

Cesar Giovanny Delgado Banegas *

Resumen: Las configuraciones espaciales en el espacio interior concentran, hoy, un campo de investigación importante. Jorge Pokropek, en sus trabajos sobre la espacialidad arquitectónica y las lógicas de coherencia para la interpretación y producción del diseño interior, propone un corpus teórico, que en este ensayo se pone en discusión en las obras de Zaha Hadid. Este ensayo concentra su atención en el campo de los espacios interiores y su configuración, desde la geometría, la teoría de la percepción y el trabajo de configuraciones espaciales, como discursos operativos del hacer para el diseño de interiores.

Palabras clave: Configuraciones espaciales - fusión de continuo - diseño de interiores, geometría, percepción visual, experiencia estética.

[Resúmenes en inglés y portugués en las páginas 132 - 133]

Afiliación institucional: Universidad del Azuay, Cuenca-Ecuador.

${ }^{(*)}$ Diseñador de Interiores, Ingeniero en Marketing y Negociación Comercial Internacional, docente investigador en la Facultad de Diseño de Universidad del Azuay en CuencaEcuador. Magíster en Proyectos de Diseño por la Universidad del Azuay, Máster en Habilidades Directivas de Negociación y Comunicación por el Instituto Eurotechnology de La Coruña - España. Co-director del Equipo de Publicaciones de la Revista DAYA: Diseño, Arte y Arquitectura. Actualmente cursa el Doctorado en Diseño de la Universidad de Palermo en Argentina.

\title{
Introducción
}

La instrumentación operativa del diseño de interiores, poco a poco se convierte en un campo de investigación y de reflexión teórica importante. Los productos, resultado del campo de esta especialidad del diseño provocan la necesidad de estudiar los mecanismos, que desde la academia se están cimentando, para afrontar la praxis proyectual de esta disciplina profesional, relativamente nueva.

En la segunda mitad del siglo XIX el diseño emerge como una disciplina académica y profesional, y sus distintas especialidades empiezan a desarrollarse de forma distinta en los 
países de América Latina. En el Ecuador, desde donde se escribe este artículo, la primera escuela universitaria de diseño nace en 1984 y el diseño de interiores se convierte en la última rama de especialidad. Como en la historia de las distintas especificidades académicas y profesionales, el diseño empieza a irrumpir en campos donde antes primaba la actividad empírica u otras ramas profesionales como la arquitectura.

Las primeras incursiones profesionales van dejando huella sobre los distintos escenarios de actividad social. Si bien la generación del diseño no se posiciona con solidez en el contexto ecuatoriano, es cuestión de tiempo que este se desarrolle en la cotidianidad social y económica.

En el campo académico empiezan a elevarse voces sobre marcos teóricos que vayan configurando la disciplina. Hoy el pensamiento relacional y complejo permite articular distintas posturas para construir la noción de forma en el diseño interior. Estudiar la forma en el espacio interior desde un solo punto de vista resulta simple y reduccionista, más bien hay que abordar la forma desde diferentes posicionamientos y variables para encontrar en ese recorrido las relaciones existentes entre los enfoques. (Cordero, 2017)

En la actualidad, una serie de factores -disciplinas- se relacionan con el objetivo de crear ese corpus teórico, necesario en la disciplina del diseño interior. Estudios de Semiótica narrativa, el signo cultural, desde la noción de estructuras conceptuales y físicas, desde la teoría de la forma - Gestalt - desde la misma noción de espacio: abstracto, sensitivo o de receptáculo, son vínculos que complejizan:

Espacio geométrico, espacio físico, espacio social o familiar, espacio económico, espacio de negocios, espacio nacional o regional, espacio histórico, espacio geográfico, espacio plástico o ilusorio, espacio teatral o espacio escénico; como los recientes cyber espacios, espacios mediáticos, informáticos, etc., son sólo algunos de los vocablos frecuentemente utilizados para referirse a categorías espaciales con significaciones muy diversas, a calificaciones y rangos semánticos que remiten a conceptualizaciones y enunciados muy diferentes. (Reinante, 2014, p.27)

Este ensayo centrará su reflexión sobre la geometría como un configurador de espacialidades y creador de espacios interiores, sin pretender, en ningún momento, dar como tácita una receta de accionar proyectual; además, en el ordenamiento de los elementos que entran en juego para la propuesta de un espacio interior, desde los planteamientos teóricos y también operativos de Jorge Pokropek:

Las categorías taxonómicas dependen de marcos conceptuales y por medio de estos esquemas clasificatorios que establecemos, podemos reconocer similitudes y diferencias entre los objetos.

Toda construcción de conocimiento sobre una organización implica establecer una clasificación de sus partes y una explicación sobre los principios que rigen el rol, tamaño, proporción y ubicación de cada una. Esta metodología de análisis no sólo es vigente sino insoslayable. (2020, p.21) 
Durante décadas la arquitectura moderna cimentó la noción de forma en la abstracción, la geometría se posicionó como la operatividad por excelencia, también en el diseño, y se fueron convirtiendo en el lenguaje disciplinar y también en el lenguaje del contexto social. La Gestalt y luego la Semiótica empezaron a configurar las bases conceptuales del diseño, y sus debates se fueron extendiendo y complejizando.

\section{El interior, un espacio perceptualmente geométrico}

A lo largo de la historia, la resolución arquitectónica ingenieril y de diseño, estuvo relacionado con la geometría, es innegable que el recurso abstracto haya configurado el sistema de lenguaje de la arquitectura y de los espacios interiores. La realidad física de los volúmenes arquitectónicos y de los espacios interiores, que en el mismo se diseñan, da como resultado una estructura. "Esta estructura abstracta o matriz posee una "geometría", una lógica que reúne y separa un conjunto de líneas, puntos y áreas desde una intención configurativa." (Pokropek, 2020, p.21). Ejemplo en imagen 1.

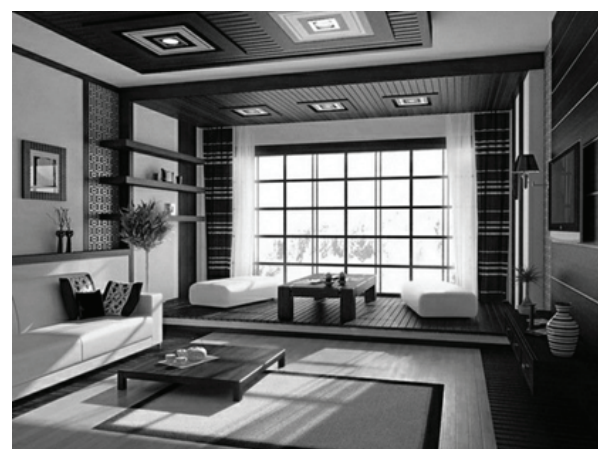

Imagen 1: Sala de estar de estilo Zen. Lectura de elementos geométricos que configuran el espacio interior. Fuente: DeInteriores.es » Blog de diseño de interiores » (2016)

La academia y la convivencia cotidiana con espacios resueltos por envolturas geométricas han instrumentado las formas de los objetos o elementos que configuran el espacio interior desde lo disciplinar y lo empírico: pisos, cielos rasos, puertas, ventanas, mobiliario, panelería... y éstas formas se han convertido en signos, en lenguaje, en significación.

En este sentido, la percepción es un paso hacia la comprensión e interpretación del mundo, de los espacios interiores, no para controlarlo sino para producir sentido ${ }^{1}$. (Ciafardo, 2008) La Teoría de la Gestalt, que en su momento propuso leyes de universalidad desde el ámbito psicológico, y que también en su momento fue altamente criticada por no tomar en consideración al contexto, cultura, variables históricas o aportes del observador, es altamente instrumental en el diseño de interiores; hoy, tomada como principios o condiciones generales que relacionan al sujeto con los objetos del espacio: 
En este contexto epistemológico se afirma que es la geometría la que define un horizonte cognitivo para que pueda interpretarse una idealización del espacio. Y es en el marco de esta disciplina, y sobre la base de utilizar ciertos postulados iniciales una vez legitimadas las relaciones entre símbolos, donde matemáticamente hablando puede manifestarse el espacio «real» y sus explicaciones en ese sentido. (Reinante, 2014, p.30)

La experiencia estética, que se establece en esa constante relación sujeto - geometría, se adapta plenamente en la construcción de la expresión con las premisas ya conocidas desde la Gestalt:

a) Figura - fondo. Es la ley básica de toda percepción visual. Plantea la oposición o tensión entre un campo que se presenta homogéneo o neutral, el fondo, frente a una unidad óptica que prevalece y se distingue, la figura.

b) Proximidad. Se refiere a un patrón que establece por distancias y contigüidad el reconocimiento de unidades en un conjunto.

c) Semejanza. Los elementos similares por forma, color, tamaño, textura, etc., tienden a agruparse formando conjuntos o subconjuntos.

d) Continuidad. Un conjunto de elementos planteados en sucesión tienden a mantenerse unidos.

e) Cierre. Se refiere a la tendencia que presentan las figuras incompletas a ser completadas. (Reinante, 2014, p. 34)

Estas premisas se encuentran resueltas en las relaciones morfológicas que se producen intencionalmente por el diseñador de interiores, para producir esas experiencias estéticas. $Y$ es el que el signo de espacio interior ya está construido en gran manera: puertas y ventanas rectangulares, pisos y cielo rasos, resueltos, en gran porcentaje, por planos a una o diferentes alturas con concreciones matéricas bastante estandarizadas, tabiques y panelería y finalmente el mobiliario. Ver ejemplo, imagen 2 y 3.

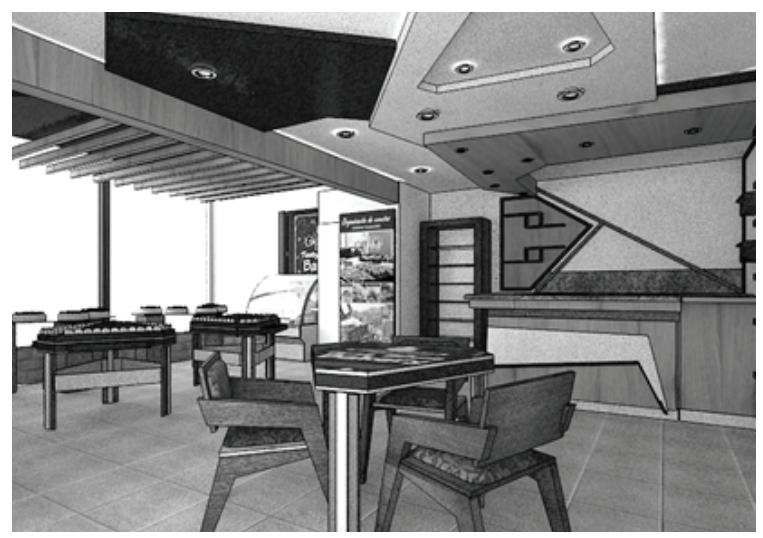

Imagen 2: Criterios de Semejanza y proximidad se evidencian en la morfología de los elementos del espacio proyectado. (Mobiliario, cielo rasos, counter). Fuente: Dis\&Mark. Interiorismo comercial. (2014) 


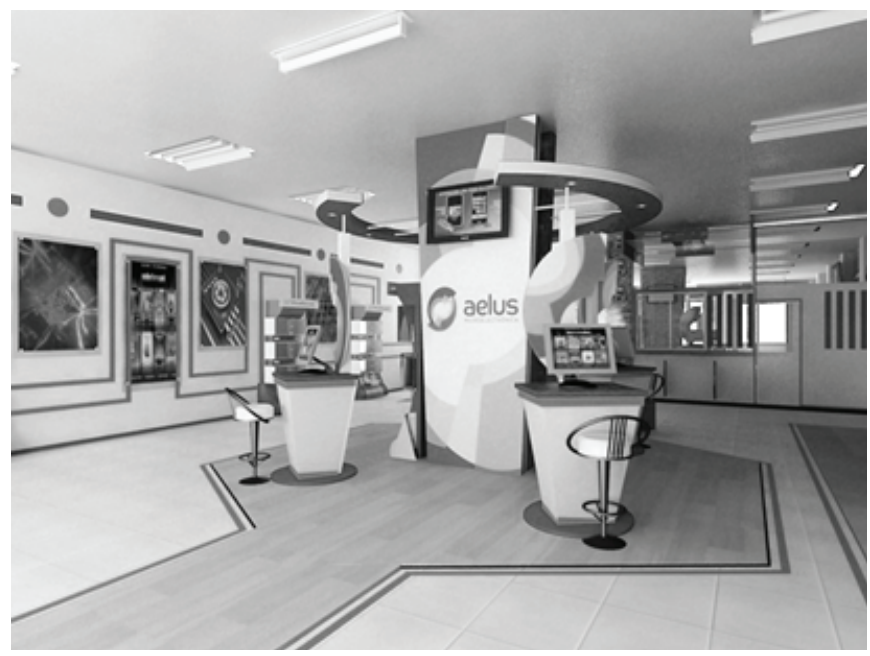

Imagen 3: Criterios de continuidad y cierre se evidencian en la morfología de los elementos del espacio proyectado. (Paredes, pisos, counters, stands). Fuente: Dis\&Mark. Interiorismo comercial. (2014)

El diseño de interiores emerge como una disciplina que se concreta, en palabras de Pokropek, (2020) en las espacialidades "envueltas" o interiores definidos por la estructura envolvente o exterior, llamada "volumetría", además aporta:

Ambas estructuras pueden y deberían analizarse o prefigurarse por separado ya que, aun siendo relativamente interdependientes, constituyen fenómenos perceptuales distintos y el campo de consideración o recorte conceptual que cada uno propone tiende a ser autónomo y a veces hasta opuesto. (p.21) Ver imagen 4.

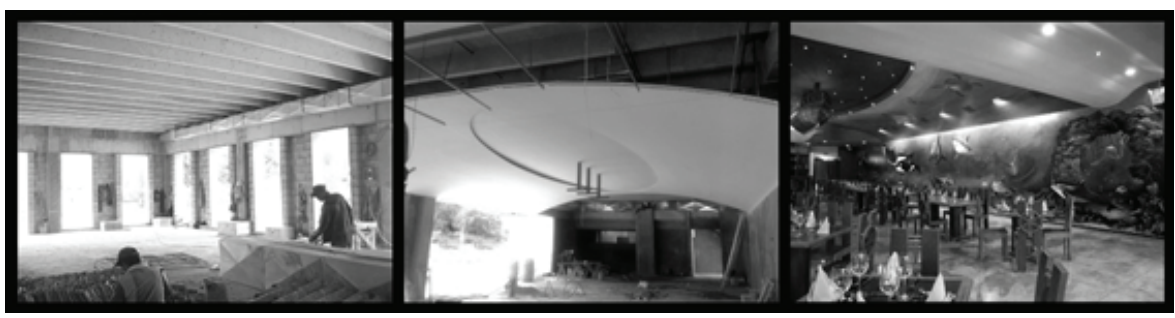

Imagen 4: En secuencia izquierda - derecha. Dato arquitectónico (envolvente): ortogonal, rígido, de hormigón | Se proyecta y concreta un espacio interior (envuelta): curva, orgánica y con expresión de agua, un fondo marino. Fuente: Dis\&Mark. Interiorismo comercial. (2014) 
En la noción de forma de los espacios interiores desde la geometría, las estructuras abstractas que configuran tanto envolventes como espacios envueltos, están relacionados con criterios de percepción. Desde esta mirada podemos proyectar, en palabras de Pokropek, a través de las lógicas de coherencia en esa estructura para la interpretación y producción del diseño de interiores, donde el nivel de "autoreferencialidad" se produce en las relaciones formales de los elementos que constituyen la forma del espacio interior.

Esta resolución se fortalece con la instrumentación de configuraciones espaciales para construir la autonomía del mensaje estético. El lenguaje formal, significante proyectado por el diseñador (relaciones entre líneas, planos, volúmenes), se configura como la totalidad de la forma que vehiculiza, por medio de la percepción, el significado o significados espaciales y estéticos.

Cada tipo configurativo espacial básico, al expresar su lógica de coherencia interna, propone su plenificación mediante la colaboración coherente del resto de las formas objetuales que en él se incluyan, desde el equipamiento, los muebles y demás accesorios.

Recordemos que el nivel de coherencia sintáctica entre las partes de una organización favorece el proceso de metaforización que desoculta el aspecto poético subyacente en el principio de acción de dicha organización, determinando así la intensidad de la experiencia estética estimulable en el usuario.(Pokropek, 2020, pp. 25-26) ver ejemplo en imagen5.

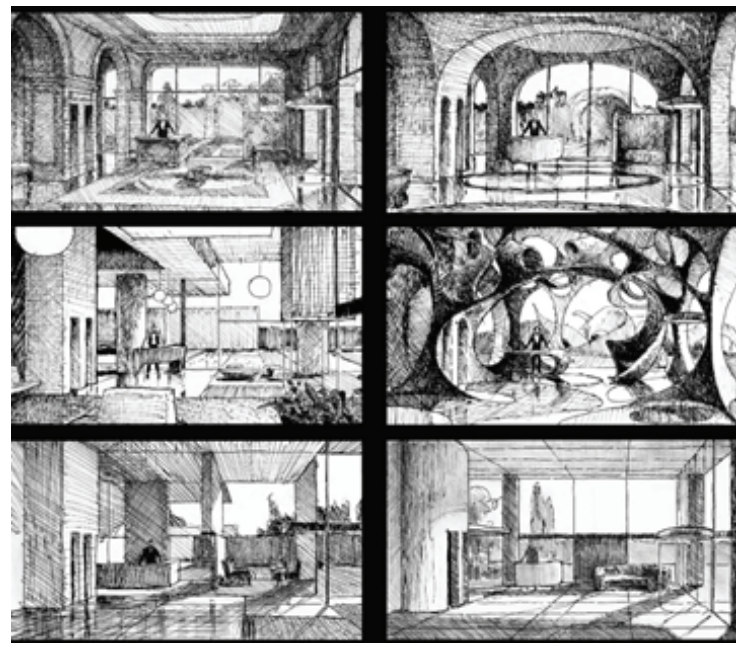

Imagen 5: Diferentes concreciones morfológicas en el espacio interior sobre la misma envolvente arquitectónica. Fuente: Imágenes del libro "ensayos sobre morfología, conducta y estética" de Héctor F. Ras, 2001. 


\section{Pares categóricos como instrumento en el análisis morfológico de espacios interiores}

Jorge Pokropek, en su trabajo "Lógicas de coherencia para la interpretación y producción del diseño interior y sus criterios de selección de formas objetuales" (2020), dice que al fenómeno interpretativo de la forma,

Vastamente estudiado por los teóricos de la Gestalt como Koffka (1973), se lo denomina "proceso de transformaciones propioceptivas". Recordemos que dicho proceso interpretativo estipula que el cerebro humano tiende a asignarle a cada estímulo visual una cadena armónica perceptual de asociaciones táctiles, gustativas, olfativas y hápticas. (...)

Sin embargo parecía necesario recordar la profunda relación entre las cadenas armónicas formales y las cadenas armónicas perceptuales interpretativas, a fin de explicitar la necesidad de esforzarse en establecer en la praxis proyectual las correspondencias armónicas entre ellas, necesarias para el incremento de coherencia interna.(p.23).

Y es que la experiencia estética en el diseño de interiores lleva un valor intrínseco altamente valorable, no único, pero definitivamente importante. Pokropek (2015) categoriza a los espacios interiores dentro de una envolvente arquitectónica como una organización global que vincula dialécticamente a esas envueltas (espacios interiores) y envolventes (arquitectura), estas categorías las define así:

1. Sostén de figuras huecas: El sujeto se desplaza DENTRO de la envuelta

2. Sostén de figuras plásticas: El sujeto se desplaza ENTRE los elementos

3. Partición de un continuo: Se exagera la noción de fluidez espacial. Estimula al sujeto a moverse y explorar

4. Fusión en continuo: Sensación de globalidad e ilimitación. Superficie Uniformemente Totalizadora.

Estas nociones de espaciales, contextualizadas en una terminología disciplinar del diseño, de totalidad y globalidad, están referenciadas claramente en la Gestalt y a su vez llevada al campo del diseño de interiores. La forma, que emerge de la instrumentación operativa, puede ser leída como una estructura coherente de relaciones perceptivas, que plenifican la lectura de unidad.

Una Gestalt (término que se asimila también a forma o estructura) es una configuración que no se reduce a la superposición o sumatoria de los elementos que la integran, sino que posee cualidades en tanto que totalidad, de modo tal que la modificación de uno solo de sus elementos puede cambiar la Gestalt en su conjunto. El todo es, entonces, más que la suma de la partes. A partir de 
aquí, la visión y la escucha no podrán pensarse como algo que va de lo particular a lo general. Por el contrario, los rasgos estructurales globales son los datos primarios de la percepción. (Ciafardo, 2008, p.2)

Para Arnheim (1993), toda imagen, todo espacio, tiene una «estructura inducida»: una compleja estructura oculta, un campo de fuerzas, de tal modo que, donde quiera se coloque una figura, ésta se ve afectada por las fuerzas de todos los factores estructurales ocultos. Esta estructura estará conceptualizada bajo los criterios y categorizaciones que el diseñador proyecta. Y es que la envuelta, propuesta por Pokropek, se configura como esa estructura invisible que establece esas lógicas de coherencia en el interior, donde se potencia a más de la experiencia estética y de las lógicas de coherencia de los elementos que configuran el espacio, "las organizaciones del mundo; y éstas, son construcciones culturales, formas simbólicas con relación a una concepción de lo visible" (Ciafardo, 2008)

\section{La obra de Zaha Hadid, lectura desde la experiencia estética y la "Fusión en continuo"}

En este ensayo reflexionamos sobre la articulación de referencialidades de lenguaje de diseño en las obras de Zaha Hadid, entre la experiencia estética y la noción de "Fusión en continuo" propuesta por Pokropek (2015). No entramos en discusiones sobre la pertinencia como obra disciplinar, ni de las relaciones culturales o sociales de sus propuestas, sino en el resultado de la forma y sus elementos de lenguaje formal. Partimos de la conceptualización desde los pares categóricos, relacionando las coherencias y las lógicas formales en la percepción de globalidad uniforme y totalizadora.

$\mathrm{Al}$ ingresar en la escala de las envueltas, las relaciones: objeto-usuario, concreción material, mobiliario, utensilios, iluminación, se potencializan para la especificidad del espacio; es decir, el campo del diseño de interiores empieza a configurar nuevas posibilidades de habitabilidad de los espacios a nivel funcional, sensitivo, sensorial, estético, de confortabilidad y calidad de vida. "no todas las formas diseñadas habitables estimulan experiencia estética con la misma intensidad (...) para que la forma arquitectónica alcance esa condición y pueda entenderse como forma artística, deberá poseer una configuración formal capaz de expresar un mensaje estético" (Pokropek, 2015, p.21), y es en este campo, en dónde el diseño de interiores se siente y desarrolla de manera cómoda.

De la obra de Zaha Hadid tomaremos el componente visual, para analizar esas lógicas de coherencia que se proyectan en el espacio en un sentido de homogeneidad, totalidad y correspondencias morfológicas entre los elementos que conforman el espacio interior. Ver ejemplificación en imágenes 6 y 7 . 

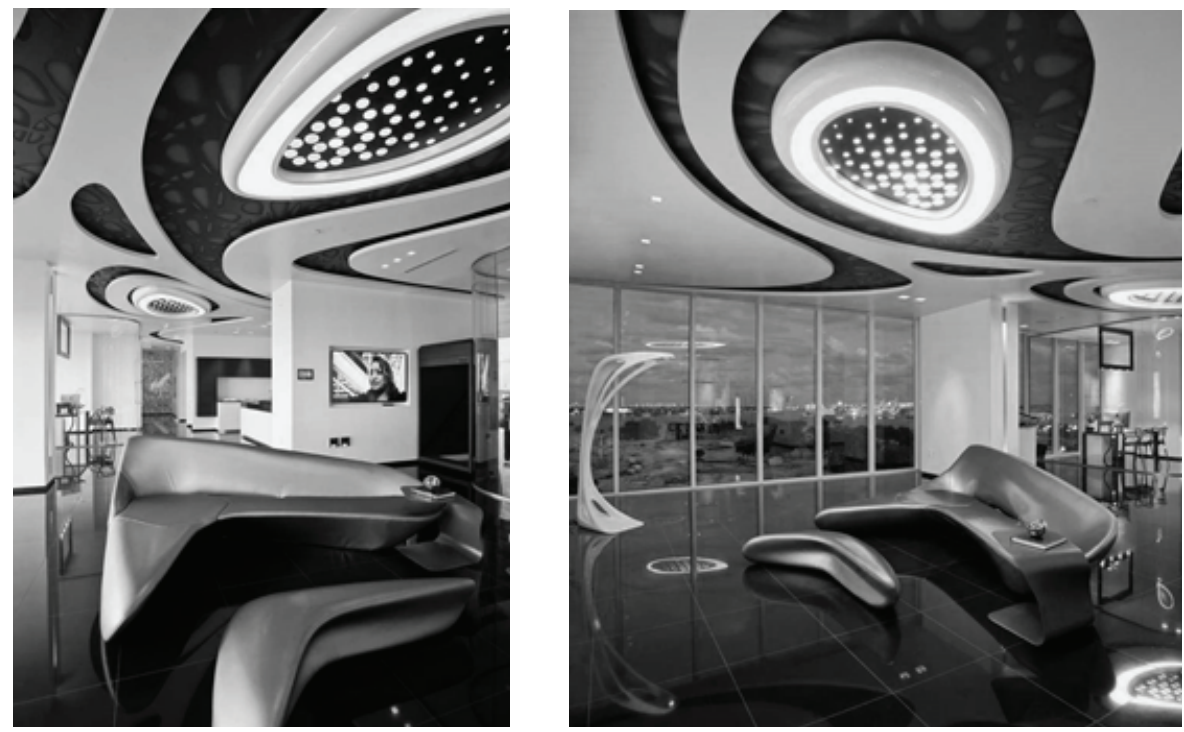

Imagen 6 y 7: Espacios interiores: Envueltas, obra de Zaha Hadid, la categorizamos como Fusión en continuo. Fuente: (Interior Design Zaha Hadid, 2019)

En las construcciones de la percepción y del mundo en sí, la noción del espacio interior es tan antigua como el hombre, y este ha venido deconstruyéndose y volviéndose a construir según la sintonía cultural de su momento. Está claro que en la contemporaneidad, la relación con la arquitectura tiene más nexos que en otros momentos. En esa relación del espacio envolvente, el uso del espacio, el sujeto que usará ese espacio, la función con la que se proyectó esa envuelta, permite la construcción de las nociones de interpretación objeto - sujeto.

Se podrá decir, entonces, que la subjetivación del espacio da lugar a una idea muy distinta conforme el modo en que sea admitida precisamente dicha subjetivación: un desocultamiento que puede tomar los caminos de la geometría, euclidiana o no euclidiana, la fenomenología, la hermenéutica, la psicología, la física, la astronomía, etc. Presupuestos, todos, que de un modo u otro resignifican la dialéctica del vacío y el absoluto como del lugar y sus relaciones. (Reinante, 2014, p.29) 
Esas relaciones, altamente visuales en el diseño de interiores, construyen su particularidad en el componente de las experiencias estéticas, en el juego de las lógicas de coherencia formales entre los cielos rasos con el piso, con el mobiliario, con las paredes, con la envolvente, con la iluminación, y en esas relaciones se potencia el desarrollo disciplinar específico; en esta secuencia coherente de la forma sólidos o huecos, virtuales o reales, cuya percepción propone una lectura de una narrativa o argumento que se presenta en los actos de celebración o ritos sociales. (Pokropek, 2015). Ver imágenes 8, 9, 10 y 11.
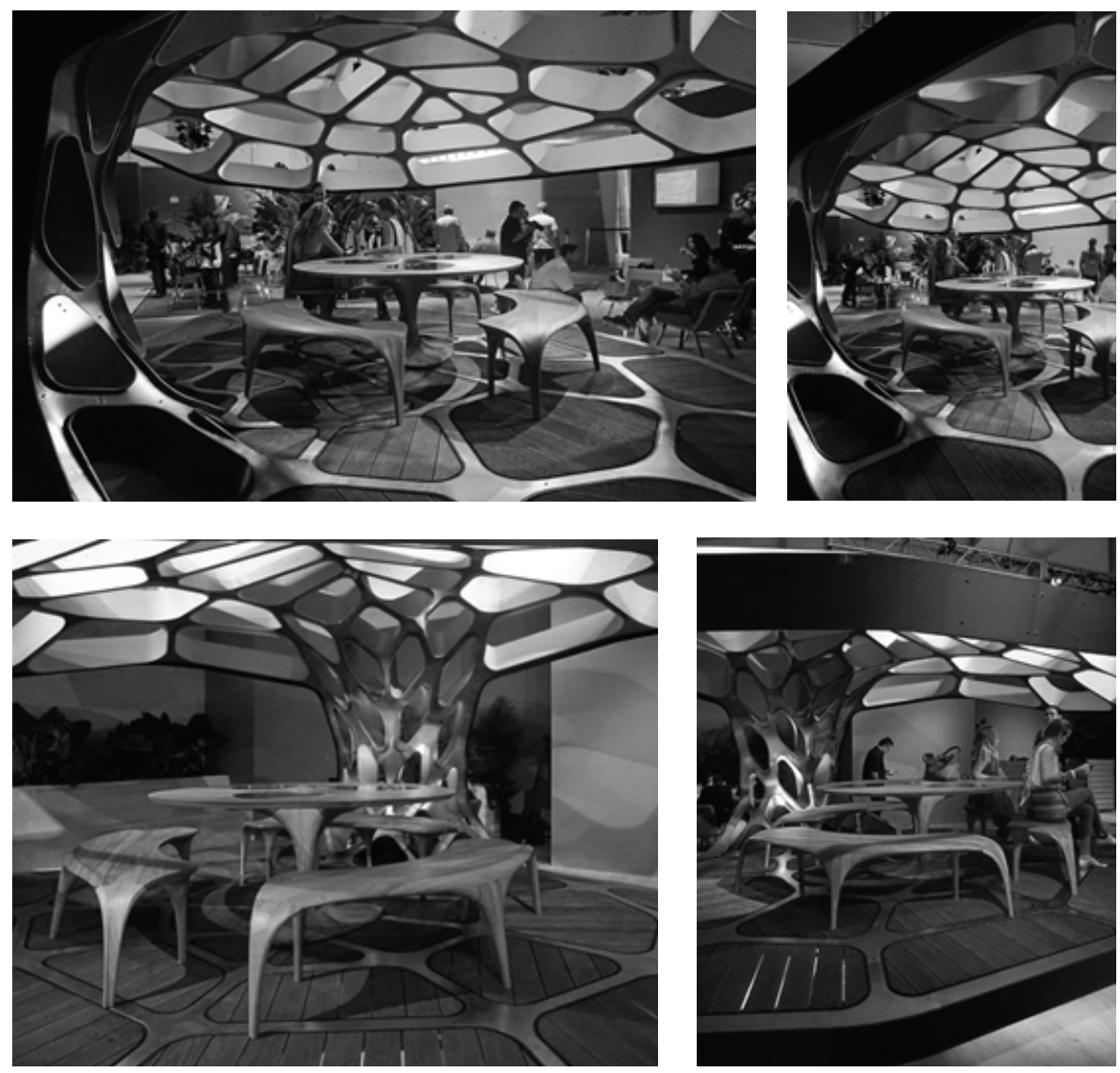

Imagen 8, 9, 10 y 11: Relaciones morfológicas entre los elementos constituyentes del espacio interior y relaciones por el todo visual. Ejemplificación de las lógicas de coherencia para la configuración de un espacio interior en fusión de continuo. Fuente: (Contact Revolution Precrafted Properties, 2018) 
La lectura de estas relaciones totalizadoras está en la geometría, se materializa a partir de la proyección geométrica de la totalidad y de sus componentes a escala, así: el cielo raso abrazador, que se asemeja a la estructura de un panal de abejas, se ve "reflejado" en el piso, sin antes pasar construyendo la mesa y las bancas. El grado de semejanza de las formas se sintoniza en continuo. La materialidad en estos ejemplos, si bien armonizan la totalidad, tiene como lectura dar autonomía a cada elemento, de manera probablemente intencional. Es justamente la noción de "fusión de continuo", la que se evidencia en estas obras, donde las relaciones de cada elemento de las envueltas diluyen sus particularidades para provocar una percepción homogenizadora, determinando la experiencia espacial en la coherencia morfológica que se da entre las partes. Así también, el campo de la concreción material en relación con el lenguaje morfológico se potencia al momento de incluirlo en la constitución total de la forma. Podemos hablar de espacios en fusión de continuo homogéneos y otros heterogéneos; sin embargo, "en ella se exalta la tensión dialéctica entre las partes y el todo." (Pokropek, 2015, p.119). Ver imagen 12 y 13.

Las lecturas de homogeneidad y hetorogeneidad en esta noción tendrán justificaciones y argumentos muy específicos, pues la fusión siempre estará presente en la totalidad de la forma, en la mixtura intencionada de las entidades espaciales provocadas. En esta conceptualización el criterio de equilibrio es pertinente como un instrumento operacional de diseño.

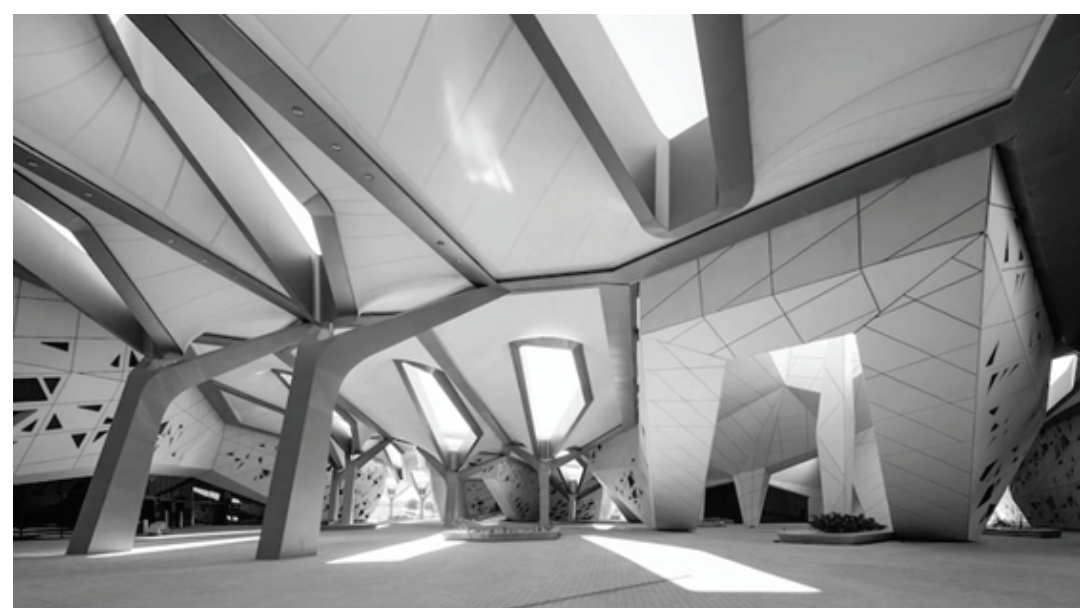

Imagen 12: La Galería de Nuevo video celebra la complejidad prismática de Kaha SAC de Zaha Hadid Architects en Arabia Saudita. Fuente: (Fotografía de Hans Georg Esch. s/a) 


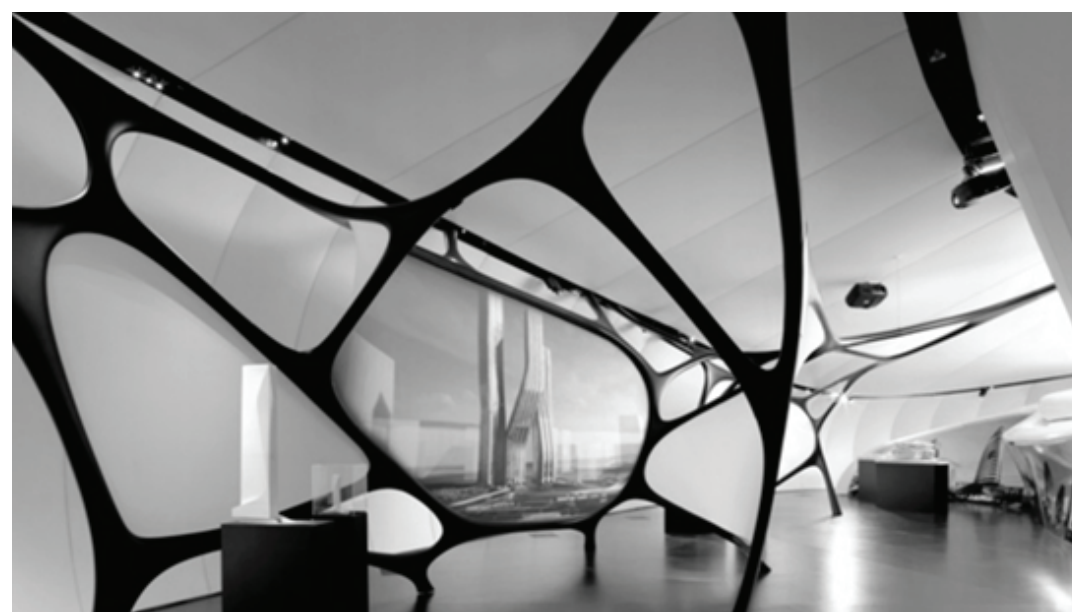

Imagen 13: Esta obra de ZahaHadid ejemplifica la noción de fusión en continuo homogéneo. Fuente:(Interior Design Zaha Hadid, 2019)

En este caso, la construcción de la experiencia estética descansa, fundamentalmente, en las lógicas de repetición o semejanza de las entidades que configuran la espacialidad. "Estas estructuras rítmicas sintácticas configuradas por la repetición y transformación evidente de entidades a lo largo de la trayectoria espacio-temporal que el fruidor recorre son, insistimos, el factor básico y necesario para el estímulo de la experiencia estética." (Pokropek, 2015, p.120) Ver imágenes 14, 15 y 16.

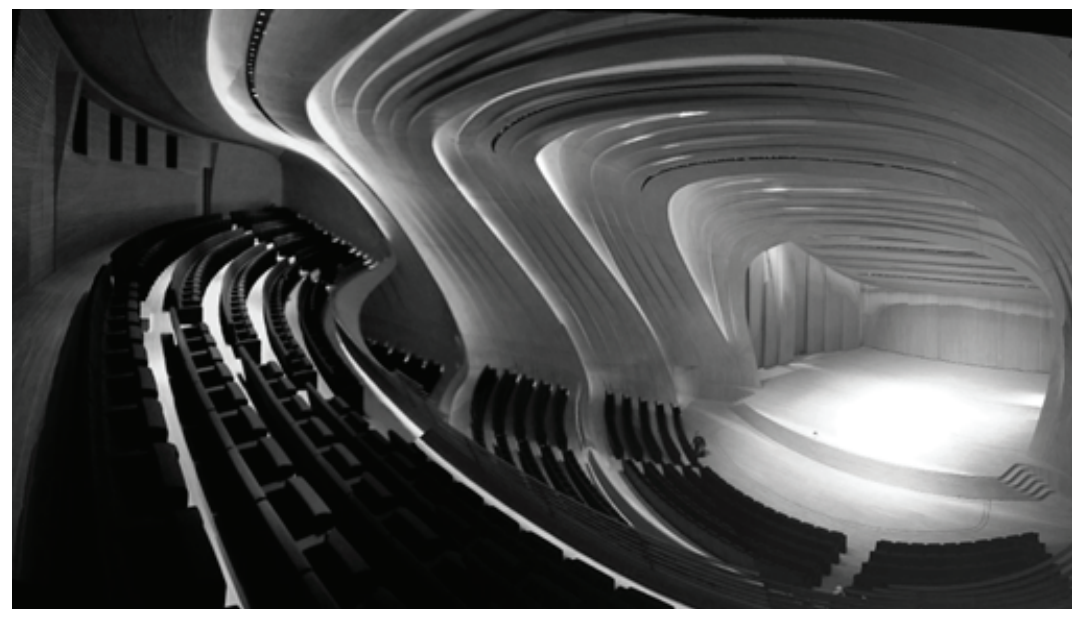

Imagen 14: El Centro Cultural de Heydar Aliyev, proyecto de Zaha Hadid. Fuente: (Diseño y Fasión ,2017) 


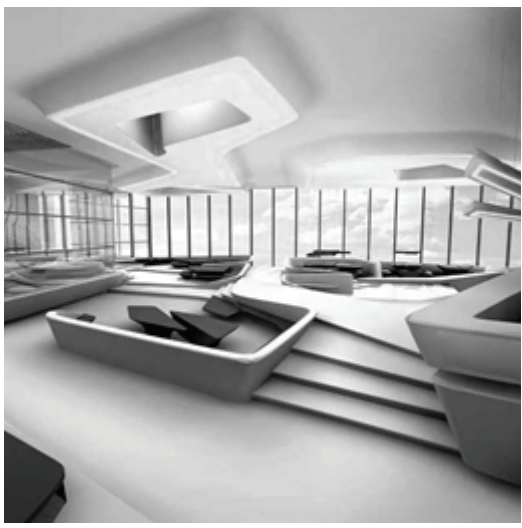

Imagen 15: Espacios interiores de Zaha Hadid. Fuente: (Interior Design Zaha Hadid, 2019).

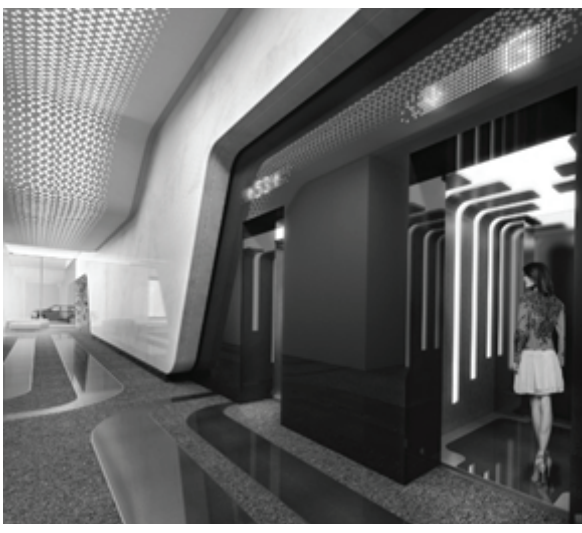

Imagen 16: Espacios interiores de Zaha Hadid. Fuente: (Interior Design Zaha Hadid, 2019).

\section{A manera de cierre}

En la contemporaneidad la emergencia del conocimiento no se produce en pensamientos deterministas, estas nociones de abstracción se han convertido en diálogos cargados de significados en ese vínculo de geometría y estética, es decir arte simbólico de los espacios interiores resueltos con un lenguaje geométrico que se configura en las relaciones.

El campo estético, variable importante en este artículo, depende del juego de relaciones que se proponen en las categorías espaciales para configurarlo. Siendo así, en esta postura, la obra de Zaha Hadid es categorizada como una forma escultórica, en este punto, Ciafardo (2008), aporta:

Hay un territorio común entre el diseño y las artes plásticas (incluso mayor que entre algunas artes plásticas entre sí) en el tratamiento de las funciones perceptuales, de los criterios interpretativos y de las intervenciones culturales y psicológicas en esa percepción.

De hecho, la distinción entre lo artístico y lo útil no se sostiene ni siquiera en la propia historia del arte occidental, la cual incluye la presencia de innumerables objetos que son a la vez funcionales, simbólicos y estéticos (retablos, mobiliario francés, joyería, tapicería, etc.). (p.13)

Por otra lado, los marcos teóricos se construyen a partir del argumento de las variables y categorías que emergen de la práctica y del discurso proyectual.

Durante toda la línea histórica de la creación humana, el hombre ha clasificado los quehaceres artísticos según el ámbito en el que se desarrollen, bien sean en lo bidimensional (pintura, dibujo, fotografía) o en lo tridimensional (escultu- 
ra, instalación, performance), en la contemporaneidad los límites entre estos ámbitos son trasgredidos, mezclándose así diferentes quehaceres de la creación, el dibujo se vuelve pintura, la pintura se vuelve fotografía, la fotografía se vuelve performance, el perfomance se vuelve videoart, el videoart se vuelve instalación, la instalación se vuelve escultura y la escultura se vuelve arquitectura. (Zapata, 2012, p. 13)

Pokropek en su trabajo (2015) construye un importante aporte al diversificar o clasificar las estructuras de la forma en los espacios interiores, a los que denomina envueltas, y en esas categorías la noción de fusión de continuo muestra cómo, en la lectura perceptiva del sujeto, entran en juego las lógicas de coherencia espacial y al mismo tiempo la lectura disciplinar de la experiencia estética.

Por otro lado es importante dar valor a la voz que se va sentando sobre la disciplina del diseño de interiores desde la arquitectura, sus relaciones y también sus controversias. En este punto las envueltas se convierten en una disciplina específica de análisis y profundización, ver el diseño desde el diseño.

Lo construido es siempre dador de aperturas, configurador de espacios que saben de su provisionalidad. ¿Cómo se entiende, entonces, el puente de la fotografía? Como el símbolo de la construcción que niega la interinidad del modo de habitar propiamente humano. (Bejarano, 2012, párr. 7)

Es que las disciplinas se construyen con argumento, con discusión y con práctica; los espacios interiores, en sus emergencias teóricas, merecen una suerte de aprendizaje, éstos, como las demás formas -objetos proyectados- conviven físicamente con otras formas en una relación permanente, pues no están aislados en el contexto, e influyen en ellas. "Los ambientes no constituyen envolturas pasivas, sino más bien procesos activos invisibles. Las reglas fundamentales, la estructura penetrante y los patrones generales de los ambientes" (McLuhan, 1967, p.68).

Las nociones de espacialidad y sus tipos configurativos hacen del diseño de interiores el objeto de estudio al momento de encontrar los recursos y las miradas de operatividad de su disciplina. El espacio "de esta manera está vinculada estrechamente con los mecanismos de percepción y la memoria de la experiencia previa” (Cordero, 2017, p.69) y la disciplina del diseño toma de esta realidad para configurar sus emergentes teóricos.

Como estudiosos del diseño y su morfología debemos y podemos explicitar cómo lograr "orden" en la complejidad de la contemporaneidad, configurando con sentido una red intencionada de lógicas proyectuales. "Aquí interesa destacar que, desde nuestro enfoque como diseñadores siempre nuestros productos deberían expresar algún tipo de orden, aún el "orden en el desorden". (Pokropek, 2015, p.124).

Finalmente, cerraremos este ensayo indicando que todos estos tipos de configuraciones espaciales brindan excelentes posibilidades de exploración proyectual en el campo del diseño de interiores, pues los campos de apertura de discusión cada vez se abrirán con mayor contundencia, por un lado hemos abordado el campo de la geometría, con lo que 
estamos muy relacionados en la cotidianidad proyectual, la percepción visual y sus ya conocidos aportes, y por último los aportes de las lógicas de coherencia para la interpretación y producción del diseño interior y sus criterios de selección de formas objetuales.

\section{Notas}

1. "Lo más relevante y característico del interpretativismo son los significados de la conducta humana, la cual tiene carácter de signo. El enfoque interpretativo propone la comprensión de la acción humana." (Barbera \& Inciarte, 2012, p. 201).

2. Estamos refiriendo al "lenguaje" en cuanto a unidades y sintaxis de los elementos constitutivos de la forma. Es una interpretación de la estructura formal y también una manera de pasaje entre abstracción y concreción de las formas. (Giordano, 2002)

\section{Referencia bibliografía de imágenes}

Imagen 1. DeInteriores.es. Blog de diseño de interiores (2016). De estilo japonés interior de la casa - cómo crear un equilibrio Zen ambiente. Recuperado el 01 de febrero de 2019, de: http://andalucialive.es/de-estilo-japones-interior-de-la-casa-como-crear-unequilibrio-zen-ambiente/

Imagen 2, 3 y 4. Dis\&Mark. Interiorismo comercial (2014). Propuesta de diseño. Recuperado el 01 de febrero de 2019, de:https://www.facebook.com/dismarkecuador/

Imagen 5. RAS, Héctor Federico (1986) - Ensayos sobre morfología, conducta y estética - EUDEBA, Buenos Aires. Recuperada el 28 de enero, de: http://teoriadelaformaopt. blogspot.com/2015/02/imagenes-fundantes-del-libro-ensayos.html

Imágenes 6, 7, 13, 15 y 16: Interior DesignZahaHadid(2019). Gallery interior design roca gallery londonzahahadid, Interiors of zaha. Recuperadas el 15 de enero de 2019, de: http:// modern.hausplanen.club/interior-design-zaha-hadid.html

Imágenes 8, 9, 10 y 11: Contact Revolution Precrafted Properties (2018). This page contains all about Contact Revolution Precrafted Properties. Recuperado el 02 de febrero de 2019, de: http://kidskunst.info/linked/contact-revolution-precrafted-properties636f6e74616374.htm

Imagen 12: La Galería de Nuevo video celebra la complejidad prismática de KahaSAC de ZahaHadidArchitects en Arabia Saudita. Fotografía de Hans Georg Esch. (s/a). Recuperado el 02 de febrero de 2019 de: https://www.archdaily.com/898218/new-video-celebratesthe-prismatic-complexity-of-zaha-hadid-architects-kapsarc-in-saudi-arabia/5b48e1bbf197ccbd32000112-new-video-celebrates-the-prismatic-complexity-of-zaha-hadidarchitects-kapsarc-in-saudi-arabia-image

Imagen 14: Diseño y Fasión (2017). Lo que está dentro: El Centro Cultural de HeydarAliyev. Recuperada el 02 de febrero de 2019, de: https://etk-fashion.com/pt/that-there-intheculturalcenterGade/ 


\title{
Lista de Referencias bibliográficas.
}

Arnheim, Rudolf: (1954) Arte y percepción visual, Madrid, Alianza, 1993.

Barbera, N., \&Inciarte, A. (2012). Fenomenología y hermenéutica: dos perspectivas para estudiar las ciencias sociales y humanas. Multiciencias, 12 (2), 199-205.

Bejarano Canterla, Rosario. (2012). Ciudades descentradas. Valenciana, 5(9), 23-58. Recuperado en 24 de febrero de 2019, de http://www.scielo.org.mx/scielo.php?script=sci_ arttext\&pid=S2007-25382012000100002\&lng=es\&tlng=es.

Ciafardo, Mariel (2008). La Teoría de la Gestalt en el marco del Lenguaje Visual. Recuperado el 21 de enero de 2019 de: http://arteyanalisis.com.ar/wp-content/uploads/2016/04/Lateor\%C3\%ADa-de-la-Gestalt-en-el-marco-del-lenguaje-visual-Ciafardo.pdf

Cordero Salazar, F. (2017). La noción de forma en la imagen: ¿qué factores la condicionan?. DAYA. Diseño, Arte Y Arquitectura., 1(3), 59 - 72. Recuperado a partir de http://revistas. uazuay.edu.ec/index.php/daya/article/view/99

Giordano, D. (2002). Una interpretación de la morfología. Seminario SEMA. Seminarios de primavera 2002.

Mcluhan, M. (1967). El medio es el mensaje. Nueva York, Estados Unidos: Bantam Books. Reinante, Carlos. (2014) Morfología y espacio. Materiales para una comprensión epistémica. 1a. ed. - Santa Fe: Ediciones UNL, 2014.

Pokropek, J. (2020). Lógicas de coherencia para la interpretación y producción del diseño interior y sus criterios de selección de formas objetuales. Cuadernos de la Universidad de Palermo, Recuperado el 05 de diciembre de 2018, de: https://fido.palermo.edu/servicios_dyc//publicacionesdc/vista/detalle_articulo.php?id_libro=726\&id_articulo=15330

Pokropek, J. (2015) La Espacialidad Arquitectónica, Editorial Diseño, Buenos Aires.

Zapata, María (2012) Architectus-Sculpere: Objetos al límite entre la Arquitectura y la Escultura. Universidad Politécnica de Valencia. Recuperado el 05 de febrero de 2019 de: https://riunet.upv.es/handle/10251/14913

\begin{abstract}
The spatial configurations in the inner space concentrate, today, an important research field. Jorge Pokropek, in his works on architectural spatiality and the logic of coherence for the interpretation and production of interior design, proposes a theoretical corpus, which in this essay is discussed in the works of ZahaHadid. This essay focuses its attention on the field of interior spaces and their configuration, from geometry, the theory of perception and the work of spatial configurations, as operational discourses of doing for interior design.
\end{abstract}

Keywords: Spatial configurations - continuous fusion - interior design - geometry - visual perception - aesthetic experience.

Resumo: As configurações espaciais no espaço interior concentram, hoje, um importante campo de pesquisa. Jorge Pokropek, em seus trabalhos sobre espacialidade arquitetônica e a lógica da coerência para a interpretação e produção de design de interiores, propõe 
um corpus teórico, que neste ensaio é discutido nos trabalhos de Zaha Hadid. Este ensaio concentra sua atenção no campo dos espaços interiores e sua configuração, desde a geometria, a teoria da percepção e o trabalho de configurações espaciais, como discursos operacionais de fazer para o design de interiores.

Palavras chave: Configurações espaciais - fusão contínua - design de interiores - geometria - percepção visual - experiência estética.

[Las traducciones de los abstracts fueron supervisadas por el autor de cada artículo] 